age they weigh from eight to twelve pounds, and in the fifth year from twelve to fifteen pounds. From that age upwards the weight increases rapidly.

The results of the artificial hatching in the Weser are exceedingly promising. Thus the salmon fisheries at Hameln have been doubled in consequence during the last ten years, the tax at present paid to this town alone by the salmon fisheries being more than a thousand pounds.

In Norway, too, efforts have been made in the same direction during the last few years. Thus in 1883 the Storthing granted a sum of money for this purpose, and with this amount the Chief Inspector of Fisheries, Herr A. Landmark, has effected the marking of several hundreds of salmon and trout, chiefly on the west coast of Norway, during last autumn and winter. The marking here is effected by means of a tiny bit of platinum, $7 \mathrm{~mm}$. long, and $4 \mathrm{~mm}$. broad, being thus about the size of the nail on the little finger, which is attached by a very fine platinum wire to the fat fin of the big fish and the tail of the smaller ones. The piece has a number stamped on it, which corresponds with one in a "log" giving all the particulars as to the date the fish was marked, its weight, size, \&c.

In order to encourage fishermen to be on the look-out for these marked fish, the inspector offers a reward of two shillings and sixpence for each mark forwarded to him, if accompanied with precise information as to the spot and date when it was taken, the length and breadth of the fish, and its weight.

As these researches will tend greatly to ascertain the habits and migrations of Salmonida, the result will be watched with interest.

\section{THE TRINITY HOUSE EXPERIMENTS ON LIGHTHOUSE ILLUMINANTS}

THE great advances made during the past few years in the science of illumination have rendered it desirable, or rather absolutely necessary, that experiments should be undertaken with a view to the determination of the advantages and disadvantages attending the use of different illuminants in lighthouses. With this view the Corporation of Trinity House have commenced a series of experiments at the South Foreland.

There are at present on the South Foreland two lighthouses, known as the high light and low light, and both of these are illuminated by electricity. Near these, three experimental lighthouses have been erected for use with the electric light, with gas and with oil respectively. The electric apparatus consists of three arc lamps and three magneto-electric machines made by Baron de Meritens. The lamps are placed one above the other in the tower. The carbons being used are "compound carbons," made up of many small rods of carbon of square section, coated with copper, and Siemens's "core-carbons," made of gas-carbon, with a central rod of graphite. When worked up to their full power, each lamp is estimated to be capable of giving a light equal to 30,000 candles.

The second tower is fitted up with Mr. Wigham's gasburners. To supply the burners a small gasworks, fitted with retorts, purifiers, and a gasholder capable of holding about 5000 cubic feet, have been erected near by. The tower contains four burners, one above the other, each burner consisting of concentric rings of jets. The total number of jets on each burner is Io8, making a total on the four burners of 432 jets; but the outer rings may be removed when less light is required: so that each burner may be used with $28,48,68,88$, or Io 8 jets. A talc chimney above the flame produces the necessary draught; no glass or talc is placed over the most luminous portion of the flame.

The intensity of the light when all the jets on all four burners are used is stated by the inventor to be equal to
12,000 candles. The third tower is for the present devoted to the oil and gas-burners invented by Sir James Douglass. The oil is supplied from a tank to the burners under a slight pressure. One oil-burner has six concentric wicks, and has a power of 720 candles ; a second has seven wicks and a power of 1000 candles. There are three burners in the tower, placed one above the other. Each tower is provided with lenses both for revolving and for fixed lights. The highest power of the gas tower is a quadriform light, of the other towers a triform light. Besides the illuminants already mentioned, there are gas-burners from the Sugg and from the Siemens Companies, which will be tested in the lighthouse towers.

For observing the lights and testing them, a line of

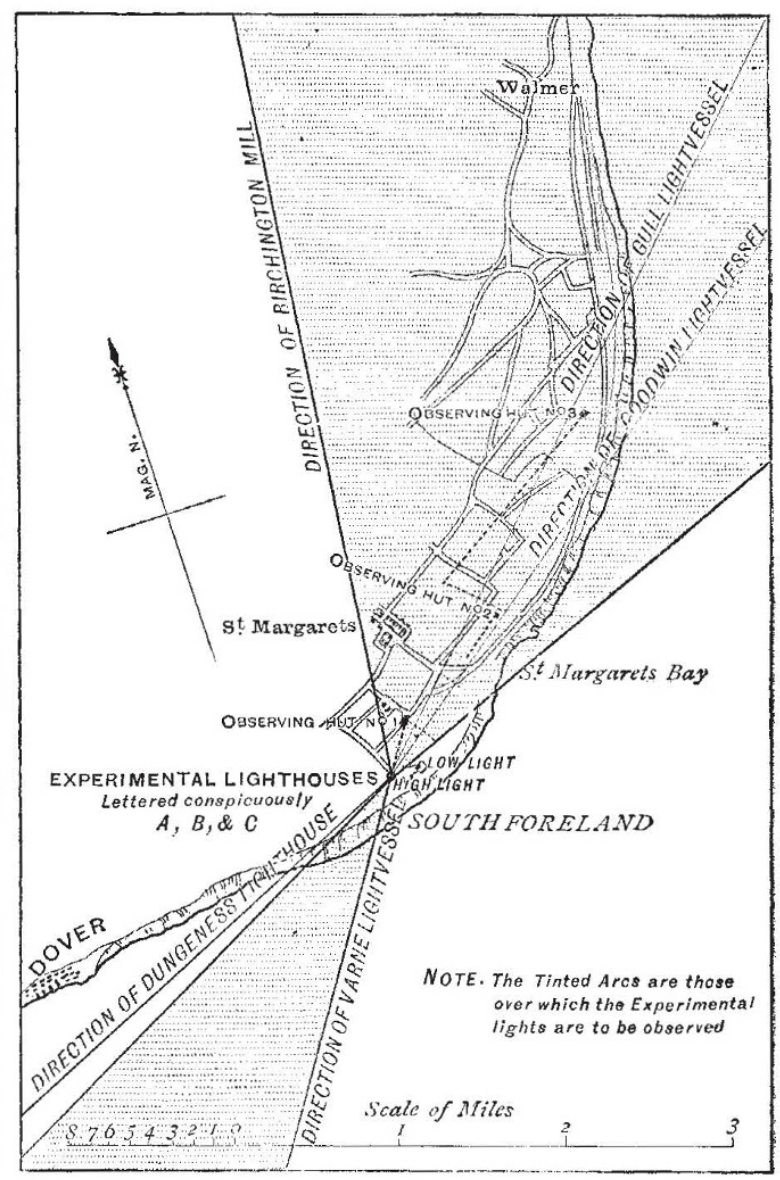

Local Map for Observations on Land.

observation has been measured out in the direction of Deal, and three huts have been erected at a distance of $\frac{1}{2}$ mile, $1 \frac{1}{4}$ mile, and $2 \frac{1}{2}$ miles respectively from the towers. These huts are fitted up as photometric observatories. The lights are focussed on one of the huts, and they are then measurcd in all conditions of weather by means of the pentane unit of light devised by Mr. Vernon Harcourt. When the weather is too thick to allow of direct comparison with the unit, the lights are compared one with another by means of a polariscope-photometer, in which the ordinary image of one light is brought to equality by means of a Nicol prism with the extraordinary image of another light. In ordinary weather a ray from the lighthouse tower enters a hole in a shutter and falls 
on a portion of a paper disk : a contiguous portion of the disk is illuminated by the pentane candle fixed on one side of the opening in the shutter. The disk can be moved on a trolley to and fro until equality of illumination is reached, when its distance from the candle is measured. This measure and the known distance of the observatory from the lighthouse give the necessary data for determining the illuminating power of the light. By these measurements, taken at different distances in various states of the atmosphere, the penetrative power of the several illuminants will be determined. For instance, in very clear weather the electric light may give twenty times the light of the oil light; a slight haze comes on and the electric light is found to be only ten times as bright. It has suffered in a greater ratio than the other. A mist blows by the towers, and the superiority of the electric light becomes less and less marked: before the lights are finally obscured the superiority has vanished. It need hardly be stated that this question of penetration is the most important point the Trinity House are called on to settle.

The principle of superposition of lights also raises an interesting point. When two lights are placed close together they can be seen at a greater distance than one light. Up to what point will this increase of range continue on multiplying the lights--without altering the intrinsic brightness of each? It may be that in thick weather the eye can detect a large area of low illumination better than a smaller area of higher illumination; and it may be that the electric light with its smaller lenses suffers from this reason in comparison with the oil and gas lights with their larger lenses.

We hope that the experiments will not be discontinued before these points have been thoroughly sifted, as they only can be satisfactorily, on the actual working scale.

We may add that the electric machines and cables are being tested by Prof. Grylls Adams, and the photometric observations taken by Mr. Harold Dixon. Mr. Vernon Harcourt is appointed to watch the experiments generally and report to the Board of Trade.

We give a plan of the district showing the point of observation, which includes the coast-guard stations and light-ships in the vicinity.

\section{THE INTERNATIONAL CONFERENCE ON EDUCATION}

THE Conference which was held at the Health Exhibition last week has achieved a remarkable success. It was attended by upwards of a thousand persons, including many of the leading teachers in English, Scotch, and continental schools, University professors, statesmen, managers of schools, and others interested in different ways in the subject of education. The interest was so well sustained that all four sections were more crowded on the last day than the first, and very general regret was expressed that the Conference should close so soon. Two circumstances mainly contributed to this result. The president, Lord Reay, by his tact and courtesy, his knowledge of foreign languages, and his cosmopolitan experience was singularly qualified, both to obtain from different continental States their most fitting representatives, and to give to these representatives when they arrived appropriate tasks and a worthy welcome. And Lord Reay was helped in the task of organising the Conference by a small but efficient committee, by whom during several previous months the work of selecting the readers of papers had been sedulously pursued. Unless pains had been taken in relation to each subject of discussion to secure that it should be initiated by a person who spoke upon it with some authority, and special knowledge, the result would have been far less satisfactory.

The Conference sat in four sections, which were at work simultaneously during five days. The first of these was devoted mainly to the consideration of questions relating to elementary education. The best and most fruitful subjects of discussion here were the Kindergarten, physical training, and the right way of inspecting, examining, or otherwise testing the work of pupils. Fröbel's principles, which have done so much to transform the system of training very young children in England, in Belgium, and in France, were expounded with much fulness of knowledge and felicity of illustration by some of Fröbel's own countrymen and disciples, as well as by ladies who have in England qualified themselves by special sympathy and knowledge to become his exponents. Closely akin to this subject were the topics of gymnastic and physical training, the better construction of schools and school apparatus, and the indirect effect of pictorial or other decorations in improving the taste and cultivating the imagination, and of increasing the scholars' interest in their work. The Swedish and other systems of bodily exercise, and the means of sense training by music and by object lessons were well discussed. On the general subject of the organisation of elementary education, which was debated in a crowded audience under the presidency of the Vice-President of the Council, the results were somewhat disappointing. Some of the teachers took the opportunity of the presence of their official chief to urge the demand with which the public have been long familiar, for grants of public money on easier conditions, and for the abandonment of the prin ciple of payment by results. But no other practical method of distributing the public money was suggested, and it was generally felt that the Vice-President had an easy victory over those who sought to attack the principles of the recently-modified Code. A more important subject was raised in the animated debate on the inspection and examination of schools, which was rendered more apposite at the moment by the appearance of the recommendations of the Select Committee of the House of Commons, recommending that there should be in England a Minister of Public Instruction, and that he should have inter alia the duty of inspecting and annually reporting on the endowed secondary schools. It was perceived that this was a step of considerable moment and significance. Under the Act of 1869 endowed schools have been re-organised, and their governing bodies and schemes of study re-constituted. But neither the Commissioners who administer that Act, nor the public, know anything of the way in which those schemes are carried out, nor of the actual performances of the schools from year to year. There was among the larger number of earnest speakers on this point, a very general agreement on two points: first that some such public supervision over the reformed foundations was absolutely necessary, in order to keep them efficient; and secondly, that as there would be in this case no grant to administer, there would not be, as in elementary schools, any need to formulate conditions as to instruction, but simply to inquire in every case what the endowed school professed to do, and to see how far it had realised its own ideal. It is rather for the purpose of knowing what the schools are doing, than for that of imposing upon them by athority any theory or official ideal that State supervision seems to be demanded in regard to endowed schools.

In the second of the sections the principal topics of discussion were connected with scientific, technical, and artistic instruction. The fact that the Conference held its sittings in the new and beautiful buildings recently erected for the City and Guilds of London Technical Institute, naturally excited special interest, and awakencd discussion as to the place which the physical sciences ought to hold in general education, as well as the special uses to which the Institute might be put in connection with the improvement of handicrafts and skilled trade. Mr. Magnus, Prof. Armstrong, Mr. Sparkes, and other 